This is a self-archived version of an original article. This version may differ from the original in pagination and typographic details.

Author(s): Heimbürger, Anneli; Keto, Harri; Isomöttönen, Ville

Title: Learning via Summarizing Infographics Assignment in Software Engineering Management e-Course?

Year: 2020

Version: Accepted version (Final draft)

Copyright: (C) IEEE, 2020

Rights: In Copyright

Rights url: http://rightsstatements.org/page//nC/1.0/?language=en

Please cite the original version:

Heimbürger, A., Keto, H., \& Isomöttönen, V. (2020). Learning via Summarizing Infographics Assignment in Software Engineering Management e-Course?. In FIE 2020 : Proceedings of the 50th IEEE Frontiers in Education Conference. IEEE. Conference proceedings : Frontiers in Education Conference. https://doi.org/10.1109/FIE44824.2020.9274229 


\section{Learning via Summarizing Infographics Assignment in Software Engineering Management e-Course?}

\author{
Anneli Heimbürger \\ Tampere University \\ Pori, Finland \\ anneli.heimburger@tuni.fi
}

\author{
Harri Keto \\ Tampere University \\ Pori, Finland \\ harri.keto@tuni.fi
}

\author{
Ville Isomöttönen \\ University of Jyväskylä \\ Jyväskylä, Finland \\ ville.isomottonen@jyu.fi
}

\begin{abstract}
This Research-to-Practice, Work in Progress Paper focuses on how learners experience creation of infographics as a summarizing assignment in an advanced level e-course on software engineering management (SEM). We have previously investigated how learners perceive infographics as a repeated reflection assignment during a requirements engineering ecourse. To complement this research project, we studied how learners experience the use of infographics as a method for summarizing a whole software engineering management course in e-education setting. The SEM course participants $(\mathrm{N}=36)$ found that infographics as a summarizing assignment required complex learning that was altogether deemed highly valuable. Participants reported on a good focus on learning tasks and learning of new skills. The participants who were in working life already found the infographics creation relevant in the light of their work (cf. authenticity). In sum, the creation of summarizing infographics appeared to yield in-depth learning with references to authenticity. The results encourage more research on the topic in computing and engineering education courses.
\end{abstract}

Keywords-Infographics, learning assignment, reflection, computing education, software engineering management.

\section{INTRODUCTION}

The focus of the paper is on how learners experience use of infographics as a method for summarizing assignment in an ecourse on software engineering management (SEM). Infographics are visual representations of information, data or knowledge. An effective infographic highlights a lot of data, is focused on relevant and interesting topics, is simple to understand, is creative and cites its data. An infographic communicates complex information in a succinct manner [1, $\mathrm{p}$. 3]. The main types include statistical, time-series, process, narrative, metaphor, comparison, hierarchical, and networks [2, 3]. Infographics have also been categorized into static, interactive, and video infographics [4].

Learners tend to experience infographics in education positively $[1,2,3,4]$. We have previously investigated learners' view of infographics in a requirements engineering e-course [13]. Volunteered students were asked to prepare an infographic three times during the course. The experiences of these students were highly positive, encouraging a more extensive use of infographics (cf. research to practice) and subsequently the preparation of the present study. In the present study, we investigated how learners experienced use of infographics as a method for summarizing a whole software engineering management course in e-Education setting.
Compared to the previous study with only five volunteered participants, a larger population of 36 case learners was recruited. This work complements findings on students' experiences but we argue that it is useful to collect students' experiences of infographics assignments in different computing contexts, as we continue to do here. Infographics are arguably not a mainstream assignment mode in computing education, and this agenda will allow the development of a sufficient understanding of infographics assignments in a computing curriculum (programming courses, capstones, etc.).

A set of questions exploring if and how preparing of infographics supported learning and how this approach compared to other learning assignments was issued to students. A thematic analysis was applied to the data received: a thematic network analysis that describes perspectives in the data at three different levels [5] produced two global (highest abstraction level), seven organizational (mid-level), and 60 basic themes (lowest level). In addition, the e-course supervisor (second author) evaluated the learners' infographics. The main focus of this paper is the students' experience of the assignment but a summary of the supervisor's observations is included. The results are discussed in relation to the previous study [14] and future work is proposed. Section II summarizes infographics in education. The context and the method are described in Section III. Preliminary findings are presented in Section IV. Conclusions and suggestions for future work follow in Section V.

\section{INFOGRAPHICS IN EDUCATION}

Infographics (information graphics) utilize visual signals for information communication and can vary from simple to complex representations; there is no threshold for something to be termed an infographic [6]. Educational literature seems to emphasize extensive use of visual information in the current age, and links infographics together with visual literacy to this prospect. Learners typically value infographics due to learning and enjoyment [7, 8]. An infographic can serve as learning material (e.g. [7]) or students can create them (e.g. [9]). The present research interest concerns creating infographics as a learning assignment. Creating infographics asks students to integrate subject area knowledge with skills that are needed for creation (see, [10]). Inquiry learning (e.g., explorative student projects) can be identified as one common setting of creating infographics (e.g., [9, 11]). The study by Gebre and Polman [10] echoes the present interest because it calls attention to use of abstraction (good learning). Gebre and Polman utilized 
infographics in secondary level science education. They observed learners' tendency to focus on depictive, iconic representations. The conclusion was that learners should be educated about how to produce presentations with abstraction. Another study by the same authors [12] investigated opinions of experts, so as to inform STEM field education of the key attributes in communicating about science. When evaluating given infographics, experts emphasized purpose, content, and representation. Furthermore, we have previously investigated learners' views in a requirements engineering course with encouraging results [14]. Infographics were used as reflective assignments at three points during the course, and were well received by volunteered participants. The results revealed learners' experiences of improved concentration on learning tasks and personalization of learning. These studies $[10,12$, 14] encouraged more research on the topic; in the present study, we explore learners' perceptions about creating summarizing infographics at the end of a large course.

\section{STUDY CONTEXT}

The target course implemented in Moodle was an advanced level e-course in SEM. This course highlights typical challenges in software engineering projects. The students learn to apply basic practices to planning and managing a software project. They will be able to analyze and identify the process model of a software project, and understand the difference between a traditional and an agile approach. The students will also learn to understand the connections of a software project to the quality system and to the process assessment and improvement. Assignments are submitted to Moodle according to the pedagogical script of the course. The supervisor monitors learners' progress and evaluates their assignments. The course consists of eight weekly assignments. The last assignment is a summarization of the whole course in a single infographic.

The research aim was to explore the applicability of infographics to such a summarizing assignment, while offering learners a new way to recapitulate and summarize the contents of the course. As creating infographics and answering to the related semi-structured questionnaire (see Table 1) were a mandatory course component, the response rate was $100 \%$, with $\mathrm{N}=36$ participants. The learners came from Finland, Germany, France, and Italy. All students studied in engineering and computing fields. Majority of them (70\%) was already in working life and the rest were basic learners. Half of the learners had not used infographics before. The other half was familiar with the concept of infographics and had also experiences in preparing them. As learners were taking IT courses, all participants could be judged to possess sufficient technical abilities to learn to use infographics tools. The course language was English. The study was carried out during the spring 2019. Using a semi-structured questionnaire approach (summarized in Table 1), the experiences of 36 learners - from now on participants - were collected, transcribed, and analyzed.

Thematic networks analysis [5, 13, 14] was used for analyzing qualitative data. The analysis was data-driven; the result categories emerged from the data. The method collects relevant parts of the textual data and organizes the perspectives in these data into network diagrams.
TABLE I. SEMI-STRUCTURED QUESTIONNAIRE

- How would you describe your overall experiences with using infographics in the last assignment of the e-course?

- What resources and/or tools were helpful to you when you created your infographics?

- What challenges did you face when you were creating your infographics? How did you overcome these challenges?

- Did infographics help you to increase your knowledge and understanding of software engineering management more than doing learning diary -type report?

- If yes, think also which aspects of using infographics were useful for you and helped you to understand the essential of the e-course material?

- Do you think that you learned also other skills when you created your infographics? Please, describe your feelings and experiences.

- Do you think that infographics supported your learning process? Please, describe how.

- Did infographics support you to focus on the subject itself? Please, describe how.

- Would you recommend using infographics for future learners in this course? Why or why not?

- What guidelines would you like to give for future learners when they create infographics for this course?

- What else would you like to share about your experiences in using infographics as study outcome?

- How would you like to develop using infographics in this course? Please give some practical examples.

Thematic network analysis proposes three classes of themes. (1) Basic Themes (small rectangles inside dotted lines in Figures 1 and 2) are simple, lowest-order themes pinpointed in the data, and say very little on their own. By the identification of similarities and differences, basic theme began to relate to each other and form organizing themes. (2) Organizing Themes (ellipses in Figures 1 and 2), as middleorder themes, assemble basic themes into clusters forming an argument or position about the situation. (3) Global Themes (rectangles in the middle of Figures 1 and 2) filter organizing themes into one insight that summarizes a comprehensive issue. Global Themes convey what the texts as a whole are about within the context of a given analysis.

All 36 learners were called to participate in the study. They were allowed to write down their answers to the semistructured questionnaire. The data received were transcribed and analyzed by the first author. A total of 145 samples from the transcribed data were filtered out and basic themes derived from these samples. The basic themes were grouped into clusters forming organizing themes, which were further summarized into two global themes. Thus, the analysis produced two thematic networks through a data-driven analysis. These thematizations were reviewed in a shared session by the first author and the second author (SEM course supervisor), which resulted in a few modifications on how themes were labeled. Moreover, the supervisor of the course evaluated all 36 infographics created. A summary of the supervisor's observations is included in the results.

\section{FINDINGS}

The thematic networks analysis produced two global, seven organizing, and 60 basic themes (emphasized in italics font below). The two global themes were named "In-depth learning" and "Multiplicative effect". In-depth learning refers 
to deep understanding in SEM due to being required to create a summarizing infographic of the whole large e-course, as was reported by the participants. Multiplicative effect concerns topics related to taking advantage of infographics in other contexts or courses, new skills and rewarding experiences reported by the participants.

\section{A. In-Depth Learning}

A thematic network titled In-depth learning (Figure 1) shows the different organizational and basic themes of in-depth learning in the participants' views. All participants reported experiences of repetition is the mother of study. They felt that the last task helped them to assimilate and memorize the course content. They said that they had to really think what this subject is about. This helped them to reconstruct the e-course material and to understand the wholeness of SEM, they reported. Participants reported that they had to re-read the whole e-course material carefully before constructing the summarizing infographics as a last assignment. Only then, they said, they were able to decide what is essential. A few participants reported also of layered distillation i.e. they told that they saw three convergent layers in the e-course: a layer of lectures, a layer of weekly assignments, and a layer of summarizing infographics.

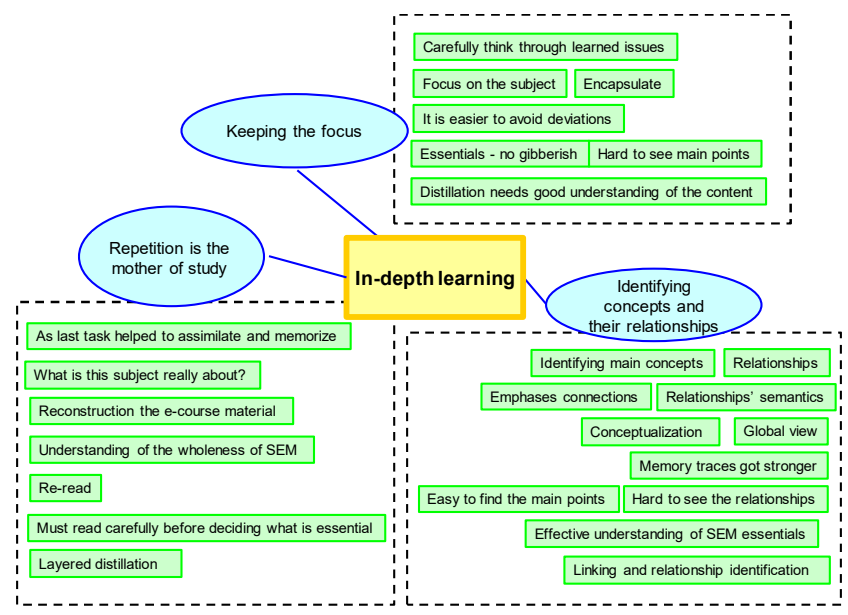

Fig. 1. Thematic network for global theme "In-depth learning".

All participants shared the feeling of keeping the focus when they were processing their summarizing infographics assignment. They reported that they had to carefully think through learned issues and they had to focus on the subject. (Authors' comment: focusing is an important skill in today's information society where there are so many information sources imposing on persons and disturbing their ability to concentrate). The participants felt it was easier to avoid deviations when focusing on essentials - avoiding gibberish. They said that the infographics should include only the main ideas of the course, and, therefore, that the topics need to be encapsulated. Some participants reported that it was hard to see the main points. They had to go over the e-course material and thus deepen they knowledge. They said that distillation needs good understanding of the content.
Issues related to identifying concepts and their relationships occurred in every participants' answers. Participants reported that it is not only important to identify the main concepts but also the relationships. They emphasized the connections between the concepts. Participants also highlighted different types of connections between SEM concepts - relationships' semantics. (Authors' comment: Relationships' semantics can include for example types of SEM process, roles in SEM processes, timing in SEM, constraints in SEM etc.). The majority of participants reported that understanding of the SEM concepts and relationships supported their impression of global view in SEM field and SEM conceptualization. In this context, some participants reported that they felt their memory trace got stronger during the SEM abstraction process. Although the importance of SEM conceptualization was emphasized by the majority of participants, some reported that it was easy to find the main points, but hard to see the relationships. Majority of the participants brought out that creating infographics was a good means for effective understanding of SEM essentials and for identification and linking relationships.

\section{B. Multiplicative effect}

The second global theme related to multiplicative effect, in other words, it concerned topics related to usage of infographics in other future contexts. Network in displayed in Figure 2. Related to rewarding experience, the participants highlighted that graphic design was fun. They felt happiness and they thought that it was great to synthesize the whole, large e-course material. On the one hand, the infographics experience was something different from writing learning diaries or essays and it was enriching, they said. On the other hand, it was timeconsuming and it required patience, they reported. Some participants told that it was hard to split the e-course material into small pieces.

All participants reported experiences related to visualization. Participants said that they learn with their eyes and that it is easy to remember when you visualize your thinking, and re-structure the e-course in your mind. This experience made learning easier and made complex concepts more accessible, they said. Participants felt that visualization process from different viewpoints (i.e. creating different types of infographics) of the whole material showed important perspectives of the SEM field. Participants, especially those who were already in working life, emphasized that visualization is a very useful and illustrative tool for $S E$ (Software Engineering) teams because visualization works well with different stakeholders with various backgrounds. However, some participants pointed out that visualization and graphic design may take too much of one's focus.

Presentation semantics inspired most of the participants. They pointed out that it is practical to keep the infographics clear and simple. In this way, it is possible to compress the data as there is no space in the (A4) infographics to go far from the essential points into details, they reported. Some participants said that they solved the challenge of space management with zooms. They also considered in their answers which type or model of infographics they will choosestatistical, time-series, process, narrative, metaphor, comparison, hierarchical, or networks. Few participants 
reported of using metaphors. They applied airport metaphor and Tetris game metaphor to create their SEM abstraction infographics. Several participants highlighted that each visual object should mean something in the infographics presentation. There is no space for decorations, they said. Some participants reported on even a deeper approach. They paid special attention to icon semantics and/or color semantics, i.e., each icon and/or each color can have a specific meaning.

The majority of participants reported that creating infographics assisted them in developing useful skills for working life. (Authors' comment: These participants took part in the e-course as mature learners-adult education. They are already in working life). They told that when they created infographics they were as if explaining the essentials of SEM to other persons, their colleagues in work. They said that they were thinking how others will see their view of SEM. The majority of participants reported that they will utilize infographics in the future in their working tasks. They reported that they learned design skills, communication skills and synthetizing skills, which all are important for software engineers, as they mentioned. They said they deepened their skills in process, timeline and workflow thinking, when they were designing and producing their infographics. They also highlighted that the decision-making on which topics were important as core issues and which topics were side issues was educational, and confirmed their skills in information filtering.

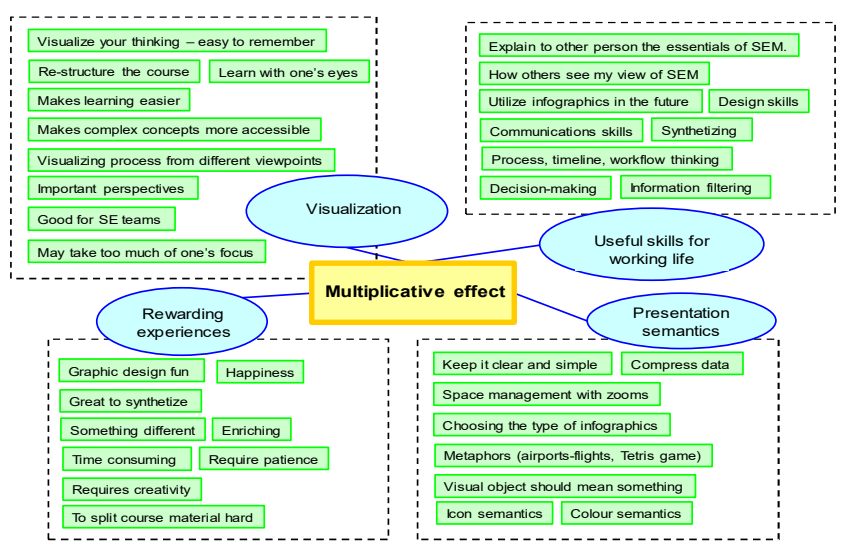

Fig. 2. Thematic network for global theme "Multiplicative effect".

\section{Supervisor's evaluation of students' infographics}

The infographics guidelines and assessment criteria for learners given by the supervisor focused on how learners had identified the core concepts of SEM and how they had constructed the infographics around those core concepts without drowning in details (abstraction assignment). The following core concepts and their close sub-concepts or attributes were expected to occur: problematic nature of software, generic life-cycle models, agile software engineering, measurement and estimation, quality management, process assessment and improvement, cultural aspects, project planning, risk management, and software business. Learners were free to use any infographics type. According to supervisor's observations, the learners already in working life identified the core concepts well; for others it was more challenging. Conclusively, the infographics assignment reporting mode and related guidelines supported learners to prepare quite compact presentations. The storylines were mostly logical and consistent. Graphic designs were creative and also metaphors were used. Generally speaking, all infographics were good; however, some of them were too detailed. The abstraction assignment seemed to be as if an optimization task between an in-depth and a facile exploration, i.e., how deep the infographics can be without being too detailed. In this task there were differences between the learners. To overcome this problem, the supervisor could pay more attention to the assignment guidelines-Fragou and Papadopoulou [15] reported positive experiences with a welldefined evaluation rubric applied to students' infographics.

\section{CONCLUSIONS}

This study reported learners' experiences of using infographics as a summarizing assignment method in a software engineering management e-course. The aim of our paper is not to claim generalization but describe learners' perspectives and experiences, and inform future research by qualitative thematization. The attitude of the participants (36 learners) towards infographics was positive and enthusiastic. Participants reported that it was challenging but fun to create infographics. They wished that more courses would use infographics as a summarizing assignment method, and planned to use infographics by themselves. Participants who were already in working life said that they will utilize infographics in their work duties. They also highlighted that they learned new technical and cognitive skills that will be useful in their study and working life. Examples of these skills are graphic design, information filtering, synthetizing, seeing the forest for the trees and identifying essential concepts and relationships between them. They also reported on rewarding experiences related to in-depth learning. Compared to our previous study [14], the present results continue to emphasize student-valued concentration on learning tasks granted by personal creation of infographics ("Keeping the focus"). The results also highlighted that in-depth learning can be supported by using infographics as a summarizing assignment method. Our future work continues to investigates these topics in other computing courses. An interesting side note was that graphical design can, on the other hand, begin to occupy too much. Moreover, the present study, focusing on an end-of-course summarizing assignment, foregrounded that producing a concise infographic out of large contents indicated complex but useful learning. This complexity was less emphasized in our previous study in which students created several infographics during the course. This comparison calls attention in our future work to how infographics are used as part of a pedagogic script. Furthermore, learners who were already integrated in working life considered infographics creation relevant. We conclude that infographics could, therefore, serve as a useful means of "authenticity". In authentic assessment, instructional approaches preferably reflect real-life, that is, learners' needs after their graduation [16]. Authenticity could, in effect, provide a framework for a large-scale comparative study on reflection/learning assignments and a framework for infographics evaluation [15] in computing and engineering education courses in the future work. 


\section{REFERENCES}

[1] M. Smiciklas, "The power of infographics. Using pictures to communicate and connect with your audiences," Indiananapolis, Indiana: QUE, 2012.

[2] G. Ru and Z. Y. Ming, "Infographics applied in design education," IEEE Workshop on Advanced Research and Technology in Industry Applications (WARTIA), pp. 984-986. September 2014.

[3] H. Naparin and A. Binti Saad, "Infographics in education: Review on infographics design," The International Journal of Multimedia \& its Applications, vol. 9, pp. 15-24, 2017.

[4] I. Damyanov and N. Tsankov, "The role of infographics for the development of skills for cognitive modeling in education," International Journal of Emerging Technologies in Learning (iJET), vol.13, pp. 82-92, 2018.

[5] J. Attride-Stirling, "Thematic networks: an analytic tool for qualitative research," Qualitative Research, vol. 1, pp. 385-405, 2001.

[6] J. Lankow, J. Ritchie J, and R. Crooks, Infographics: The power of visual storytelling. Hoboken, NJ: John Wiley \& Sons, 2012.

[7] K. Lyra, S. Isotani, R. Reis, L. Marques, L. Z. Pedro, P.A. Jaques, and I. I. Bitencourt, "Infographics or graphics+text: Which material is best for robust learning?" IEEE International Conference on Advanced Learning Technologies ( ICALT), pp. 366-370, 2016.

[8] F. Ozdamli and H. Ozdal, "Developing an instructional design for the design of infographics and the evaluation of infographic usage in teaching based on teacher and student opinions," Eurasia Journal of Mathematics, Science and Technology Education, vol. 14, pp.11971219, 2018.

[9] E. Alabdulqader, "Visualizing computer ethics using infographics," Proceedings of the 18th ACM Conference on Innovation and technology in computer science education (ITiCSE), pp. 355-355, July 2013.

[10] E. H., Gebre and J. L. Polman, "Developing young adults' representational competence through infographic-based science news reporting," International Journal of Science Education, vol. 38, pp. 2667-2687, 2016

[11] J. D. Shanks, B. Izumi, C. Sun, A. Martin, and C. B. Shanks, "Teaching undergraduate students to visualize and communicate public health data with infographics," Frontiers in Public Health, vol. 5, pp. 1-6, 2017.

[12] J. L. Polman and E. H. Gebre, "Towards critical appraisal of infographics as scientific inscriptions,"

[13] A. Heimbürger, V. Isomöttönen, H. Keto and P. Nieminen,"How do Academics Experience Use of Recorded Audio Feedback in Higher Education? Thematic Analysis". IEEE Frontiers in Education Conference, October 3 - 6, 2018 San Jose, CA, USA

[14] A. Heimbürger and V. Isomöttönen," Infographics as a Reflective Assignment Method in Requirements Engineering e-Course? FIE 2019, Proceedings of the 49th IEEE Frontiers in Education Conference, Conference proceedings: Frontiers in Education Conference, October $16-18,2019$ Cincanatti, OH, USA.

[15] O. Fragou and M. Papadopoulou, "Exploring infographic design in higher education context: towards a modular evaluation framework," Journal of Visual Literacy, 38(4), 2020.

[16] D. W. Shaffer and M. Resnick. "Thick" Authenticity: New Media and Authentic Learning. Journal of interactive learning research, 10(2), p. 195, 1999. 